\title{
RNA interference against SPARC promotes the growth of U-87MG human malignant glioma cells
}

\author{
HAIYAN LIU ${ }^{1,2}$, YUANYUAN XU $^{1}$, YUN CHEN $^{3}$, HAOWEN ZHANG $^{1}$, \\ SAIJUN FAN $^{1}$, SHUANG FENG ${ }^{1}$ and FENJU LIU ${ }^{1}$ \\ ${ }^{1}$ Department of Radiobiology; ${ }^{2}$ Jiangsu Provincial Key Laboratory of Radiation Medicine and Protection, \\ School of Radiation Medicine and Public Health, Soochow University, Suzhou, Jiangsu 215123; \\ ${ }^{3}$ Fudan University Shanghai Cancer Center, Shanghai 200032, P.R. China
}

Received May 5, 2011; Accepted June 23, 2011

DOI: $10.3892 / 01.2011 .360$

\begin{abstract}
Malignant glioma is a highly invasive brain tumor resistant to conventional therapies. Secreted protein acidic and rich in cysteine (SPARC) has been shown to facilitate glioma invasion. However, the effects of SPARC on cell growth have yet to be adequately elucidated. In this study, we constructed a plasmid expressing shRNA against SPARC, evaluated the effect of SPARCshRNA on SPARC expression and then assessed its effect on cell growth in U-87MG cells. Using plasmid-delivered shRNA, we effectively suppressed SPARC expression in U-87MG cells. Cell growth curves and colony formation assay suggested that the introduction of SPARCshRNA resulted in an increase of cell growth and colony formation. We also showed that knockdown of SPARC expression was capable of promoting the cell cycle progression from the G1 to $\mathrm{S}$ phase. However, no difference was found in the level of apoptosis. A molecular analysis of signal mediators indicated that the inhibition of p-c-Raf (Ser259) and accumulation of p-GSK-3 $\beta$ (Ser9) and p-AKT (Ser473) may be connected with the growth promotion by SPARC shRNA. Our study may provide an insight into the biological function of SPARC in glioma.
\end{abstract}

\section{Introduction}

Glioma is a malignant tumor with great invasion potential, and with a high relapse rate and poor prognosis. The median survival of patients with glioma is only 9-12 months (1). The poor prognosis in glioma patients is partially ascribed to the failure of curative surgery and resistance to chemotherapy or

Correspondence to: Professor Fenju Liu, Department of Radiobiology, School of Radiation Medicine and Public Health, Soochow University, 199 Ren'ai Street, Suzhou 215123, P.R. China E-mail: fangsh@suda.edu.cn

Key words: secreted protein acidic and rich in cysteine, RNA interference, malignant glioma, cell growth radiotherapy. Thus, investigation of more effective treatments to improve the survival of glioma patients is crucial.

Secreted protein and rich in cysteine (SPARC), a matricellular protein, plays a crucial role in modulating cell adhesion, motility and cell-matrix interactions (2,3). A growing body of evidence suggests that SPARC overexpression is responsible for the aggressiveness of many human tumors (4-10). Glioma is a highly invasive tumor as noted in studies where the overexpression of SPARC was reported in adult human gliomas either in the tumor core or at the brain-tumor interface, $(6,10,11)$. As a marker of poor prognosis, SPARC was correlated with the survival of glioma patients (12). As regards the underlying mechanisms by which SPARC contributes to glioma invasion, SPARC has been shown to upregulate MT1-MMP levels and MMP-2 activity, which degrade components of the extracellular matrix and may promote cell migration (13). Furthermore, HSP27 may mediate SPARC-induced changes in glioma invasion (14). The abovementioned results suggest that SPARC be explored as a cancer therapeutic target. However, the complex functions of SPARC and its precise role in glioma have yet to be adequately elucidated. Thus, more efforts are required to provide a biological rationale for clinical application.

In the present study, a plasmid expression vector of shRNA against SPARC was constructed, transfected into U-87MG cells and the stably transfected cells in which the expression of SPARC was downregulated successfully was obtained. Cell growth, colony formation, cell cycle distribution, apoptosis and certain signal molecules were then analyzed to detect the role of SPARC in cell growth and the relevant mechanisms.

\section{Materials and methods}

Cell lines and culture. The human malignant glioma U-87MG, U-251 and SHG44 cells were cultured in Dulbecco's modified Eagle's medium (DMEM) supplemented with $10 \%$ fetal bovine serum (FBS) and incubated in $5 \% \mathrm{CO}_{2}$ at $37^{\circ} \mathrm{C}$.

Real-time RT-PCR. Total RNA was extracted with RNAiso reagent (Takara, Japan), and $1 \mu \mathrm{g}$ was utilized for the cDNA synthesis. SPARC primers were 5'-AGGAAACCGAAGAG 
GAGG-3' (forward) and 5'-TTGTGGCAAAGAAGTGGC-3' (reverse). 18S primers were 5'-ACGACCCATTCGAACG TCTG-3' (forward) and 5'-CCGTTTCTCAGGCTCCCTC-3' (reverse). PCR conditions were $50^{\circ} \mathrm{C}$ for $2 \mathrm{~min}, 95^{\circ} \mathrm{C}$ for $10 \mathrm{~min}, 40$ cycles at $95^{\circ} \mathrm{C}$ for $15 \mathrm{sec}$ and $60^{\circ} \mathrm{C}$ for $1 \mathrm{~min}$. Relative expression of SPARC mRNA was calculated by normalization of the cycle threshold $(\mathrm{Ct})$ of SPARC to that of $18 \mathrm{~S}, \Delta \mathrm{Ct}=\mathrm{Ct}$ SPARC$-\mathrm{Ct} 18 \mathrm{~S}$.

Western blotting. For each assay, cells were lysed in lysis buffer (Beyotime, China) and centrifuged at 14,000 rpm for $5 \mathrm{~min}$ at $4^{\circ} \mathrm{C}$. An equal amount of protein was run on polyacrylamide gels (SDS-PAGE), transferred to PVDF membrane and hybridized. Immunoblot signals were detected using ECL reagent according to the manufacturer's instructions (Beyotime). Anti-SPARC antibody was purchased from Invitrogen (USA). Specific antibodies for phosphor-c-Raf (Ser259), phosphor-GSK-3 $\beta$ (Ser9), phosphor-AKT (Ser-473) and AKT were purchased from Cell Signaling Technology (USA). The antibodies were used according to the manufacturer's instructions. As a control for sample loading, the level of $\beta$-actin in each sample was determined using mouse anti- $\beta$-actin (Beyotime).

Construction of short hairpin RNA (shRNA) expression plasmids. The target site (5'-GCAGAGGTGACTGAGGTATCT-3') was identified in the SPARC mRNA sequence (GenBank ID: NM_003118). The shRNA template oligonucleotides (5'-CAC CGCAGAGGTGACTGAGGTATCTTTCAAGAGAAG ATACCTCAGTCACCTCTGCTTTTTTG-3' and 5'-GATCC AAAAAAGCAGAGGTGACTGAGGTATCTTCTCTTCCT CACAGTCACCTCTGC-3') were synthesized and inserted into plasmid pGPU6 (GenePharma, China) with the polymerase III U6 promoter. Another sequence of shRNA with no homology to any other human gene was used as a negative control. After the ligation, the plasmid was transformed into $E$. coli cells and plated on LB plates containing kanamycin and grew overnight at $37^{\circ} \mathrm{C}$. The recombinant plasmid was then confirmed by sequencing.

Cell transfection and G418 selection. Cells were plated onto a 6 -well plate and transfected with $4 \mu \mathrm{g}$ of plasmid DNA using Lipofectamine $^{\mathrm{TM}} 2000$ (Invitrogen, USA) until a confluence of $80 \%$ was achieved. The stably transfected cells were then selected by $200 \mu \mathrm{g} / \mathrm{ml} \mathrm{G} 418$ (Amresco, Solon, OH, USA) and named U-87MG/SPARC shRNA or U-87MG/control shRNA.

Cell growth curves. Cells were seeded in 60-mm tissue culture plates in triplicate at a density of $5 \times 10^{4}$ per plate. After incubation, cells were counted at the indicated time and the viability was determined by the trypan blue exclusion method. Cell numbers were plotted against the time points, giving rise to a cell growth curve.

Colony formation assay. Cells in the logarithmic growth phase were trypsinized and appropriate dilutions of cell cultures were replated in 6-well plates for colony formation assay. After 12-14 days of incubation, the cells were fixed with $10 \%$ methanol and stained with Giemsa. Colonies of $\geq 50$ cells were counted.

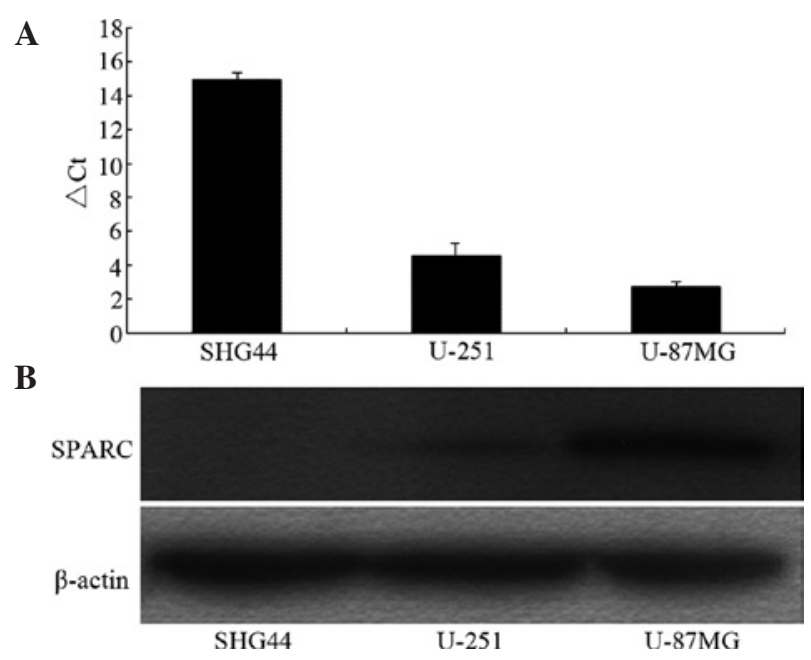

Figure 1. SPARC expression in U-87MG, U-251 and SHG44 cells. (A) Comparison of SPARCmRNA among the three cell lines by real-time RT-PCR. Data shown are the means $\pm \mathrm{SD}, \mathrm{n}=3$. (B) Cell lysates were prepared and analyzed by Western blotting for both SPARC and $\beta$-actin expression in cells.

Cell cycle analysis. The cell cycle distribution was determined by flow cytometry (Beckman Coulter). Cells were harvested, washed and fixed overnight in $70 \%$ ice-cold ethanol. Subsequently, the cells were treated with propidium iodide (PI) and incubated for $30 \mathrm{~min}$ at $4^{\circ} \mathrm{C}$ using flow cytometry.

Flow cytometry analysis of apoptosis. Cell apoptosis was analyzed by the PE Annexin V apoptosis detection kit (BD Pharmingen). Briefly, cells were harvested, resuspended, and stained with PE Annexin V and 7-amino-actinomycin (7-AAD) for $15 \mathrm{~min}$ in the dark. Samples were subsequently analyzed by flow cytometry within $1 \mathrm{~h}$.

Statistical analysis. Results were expressed as the mean \pm standard deviation (SD). Statistical analysis was performed using Statistical Analysis System (SAS) software, version 8.1. One-way ANOVA was used for multiple-group comparisons. $\mathrm{p}<0.05$ was considered to be statistically significant.

\section{Results}

Expression levels of SPARC in three human glioma cell lines. Firstly, to investigate the expression level of SPARC in different types of glioma cells, we selected the three most common studied human glioma cell lines (U-87MG, U-251 and SHG44). Comparison of SPARC expression in the three glioma cell lines was performed by real-time RT-PCR and Western blotting. The results (Fig. 1) showed that the levels of SPARC mRNA and protein were highest in the U-87MG cells, followed by the U-251 and SHG44 cells, respectively ( $<<0.01$ ). As a result, U-87MG cells were selected for transfection with the SPARC shRNA expression vector in the subsequent study.

Inhibitory effect on the expression of SPARC detected by real-time RT-PCR and Western blotting. In order to decrease SPARC expression in U-87MG, we constructed a RNA interference plasmid vector. After transfection and selection, we performed real-time RT-PCR and Western blotting analysis 


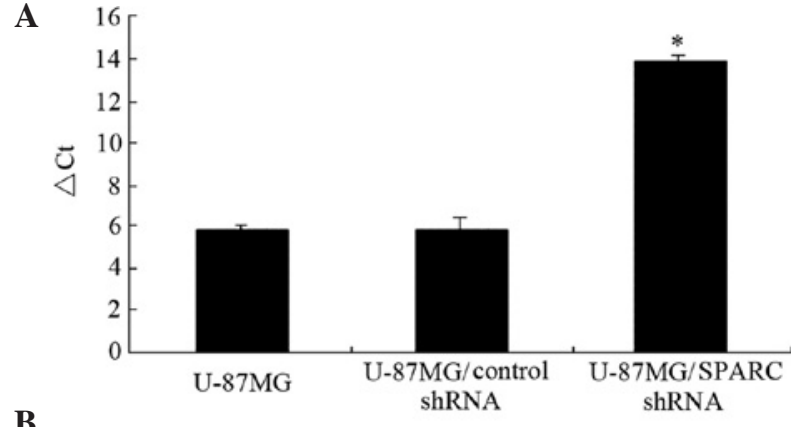

B

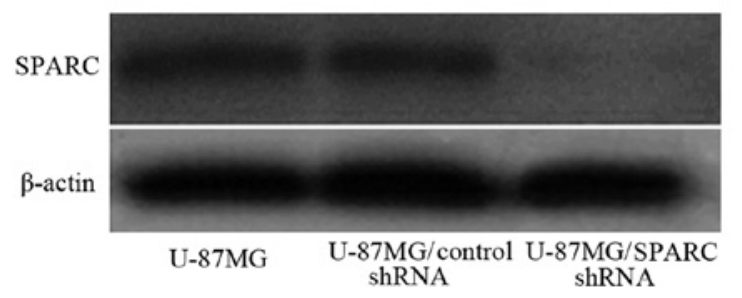

Figure 2. The effect of RNA interference on SPARC expression in cultured U-87MG cells. (A) Comparison of SPARCmRNA among three types of cells by real-time RT-PCR. Data shown are the means $\pm \mathrm{SD}, \mathrm{n}=3$. ${ }^{*}$ Statistical significance compared to U-87MG and U-87MG/control shRNA, $\mathrm{p}<0.01$. (B) Cell lysates were prepared and analyzed by Western blotting for both SPARC and $\beta$-actin expression.

to examine the expression of SPARC in U-87MG, U-87MG/ SPARC shRNA and U-87MG/control shRNA. The transfection of SPARC shRNA vector led to a marked decrease of SPARC expression in U-87MG $(\mathrm{p}<0.01)$. In contrast, no difference was found in the expression of SPARC mRNA and protein between U-87MG and U-87MG/control shRNA (Fig. 2). Results indicated that SPARC expression was downregulated effectively and stably by RNA interference.

Knockdown of SPARC expression promoted cell growth in $U-87 M G$. The growth of these cells was assayed by cell growth curves and colony formation. As shown in Fig. 3A, U-87MG and U-87MG/control shRNA cells grew in a time-dependent manner and the cell number increased to $6.34 \pm 0.10 \times 10^{5}$ and $6.13 \pm 0.06 \times 10^{5}$ cells/plate on day 7 . As for U-87MG/SPARC shRNA cells, the growth rate became significantly increased from day 1 to 6 ; and the cell number reached $1.12 \pm 0.04 \times 10^{6}$ cells/plate on day 7 , nearly twice that of control cells. The colony formation assay was used as an alternative method of evaluate the effect of SPARC shRNA on cell growth. Results indicated that compared with control cells, the colony forming ability was increased in U-87MG/ SPARC shRNA ( $<<0.05$; Fig. 3B).

The effect of decreased SPARC expression on cell cycle distribution and cell apoptosis of U-87MG. To detect the biological function of SPARC in cell cycle distribution and cell apoptosis, flow cytometric analysis was performed. As shown in Fig. 4, at $12 \mathrm{~h}$ after synchronized culture, $41.09 \pm 2.19 \%$ of U-87MG/ SPARC shRNA cells were in the $\mathrm{S}$ phase compared with only $27.47 \pm 1.41 \%$ in U-87MG and $30.44 \pm 6.00 \%$ in U-87MG/ control shRNA $(\mathrm{p}<0.05)$. However, no difference was observed in the apoptotic rate among the three types of cells (Fig. 5). Knockdown of SPARC expression appeared have little effect on the induction of cell apoptosis.
A

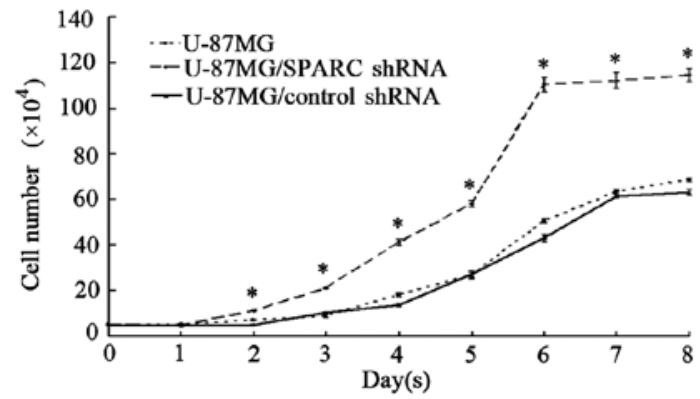

B

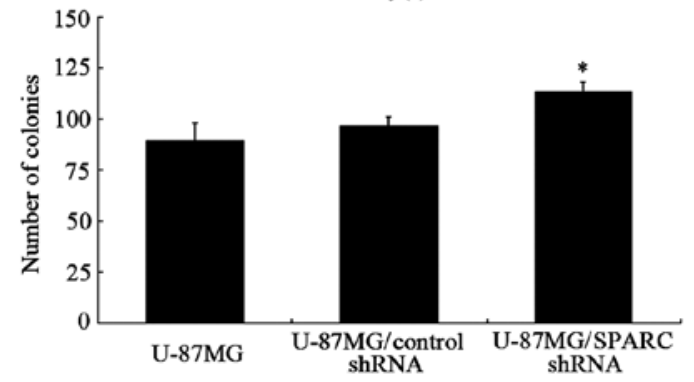

Figure 3. Knockdown of SPARC expression promoted cell growth in U-87MG. (A) Growth curves of U-87MG, U-87MG/control shRNA and U-87MG/SPARC shRNA. (B) Comparison of the colony-forming abilities. Data shown are the means $\pm \mathrm{SD}, \mathrm{n}=3$. "Statistical significance compared to U-87MG and U-87MG/control shRNA, p<0.05.

Knockdown of SPARC expression led to the inhibition of $p$-c-Raf (Ser259) and accumulation of $p-G S K-3 \beta$ (Ser9) and $p$-AKT (Ser473) in $U-87 M G$. It is known that there are numerous mediators of signal transduction pathways involving cell growth and proliferation. In the present study, changes of certain signal molecules were assessed to highlight the related signal pathways responsible for cell growth promotion by SPARC shRNA. The results showed that phosphorylated c-Raf (Ser259) protein was reduced in U-87MG/ SPARC shRNA compared with the U-87MG and U-87MG/ control shRNA cells. Moreover, downregulation of SPARC increased the phosphorylation of GSK-3 $\beta$ (Ser9). In contrast to the control cells, the phosphorylation of AKT (Ser473) was more evident in the U-87MG/SPARC shRNA cells (Fig. 6).

\section{Discussion}

Malignant glioma is a disease that presents with a relatively high recurrence rate and mortality. Despite the recent development of various therapeutic strategies, the prognosis for this cancer remains poor. Findings of various studies have shown that novel gene therapy is crucial for improving the survival rate of glioma patients. One characteristic feature of glioma is the marked ability of tumor cells to invade. A growing body of evidence has shown an important role of SPARC in glioma invasion (6-10). These studies focus on the importance of SPARC as an anti-migration target and may offer therapeutic potential against glioma. However, the role of SPARC in tumor growth has yet to be determined.

In this study, we downregulated the expression of SPARC by RNA interference. RNA interference is a potent technique of gene silencing that can specifically inhibit transcription of a target gene, to downregulate the level of the relevant protein $(15,16)$. Our study demonstrated that shRNA targeting of SPARC led to the efficient inhibition of SPARC mRNA and 
A
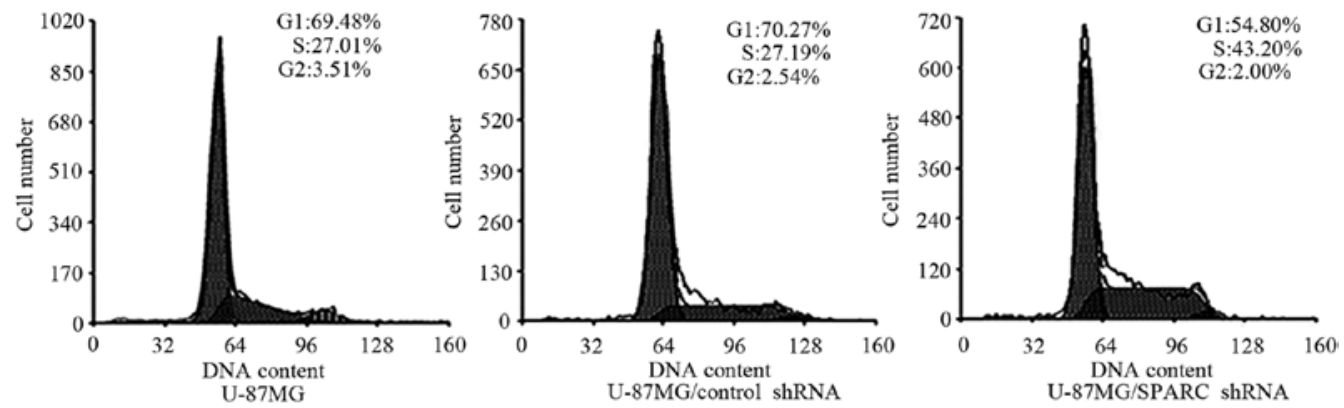

B

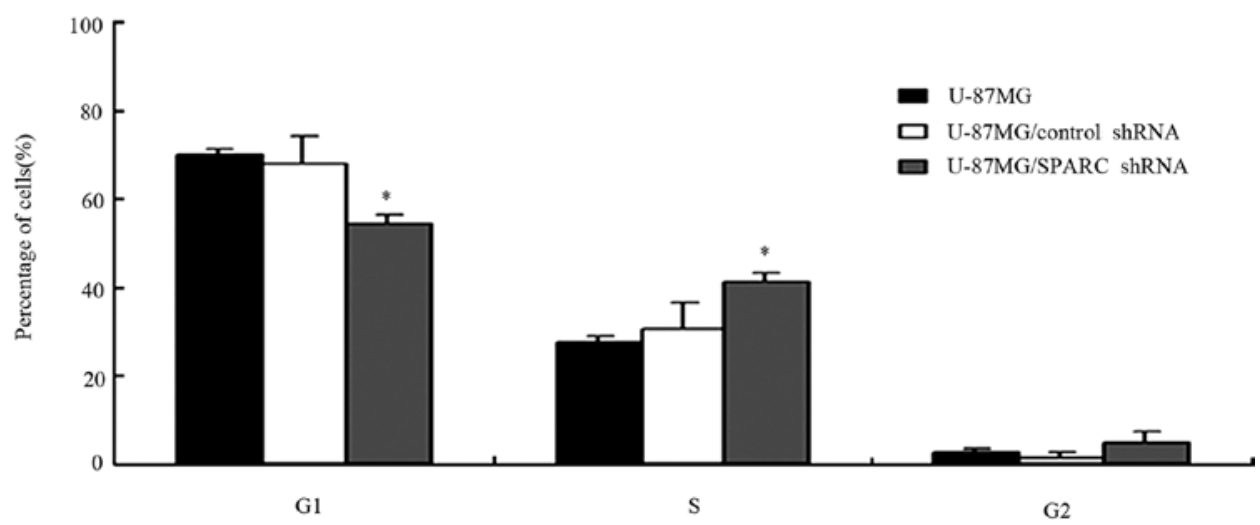

Figure 4. Effect of decreased SPARC expression on cell cycle distribution. (A) Flow cytometry of cell cycle progression. Asynchronous cultures were fixed by ethanol, stained with PI and then analyzed for DNA content by flow cytometry. (B) The histograms of G1, S and G2 phase cells. Data shown are the means $\pm \mathrm{SD}, \mathrm{n}=3$. *Statistical significance, $\mathrm{p}<0.05$.

A
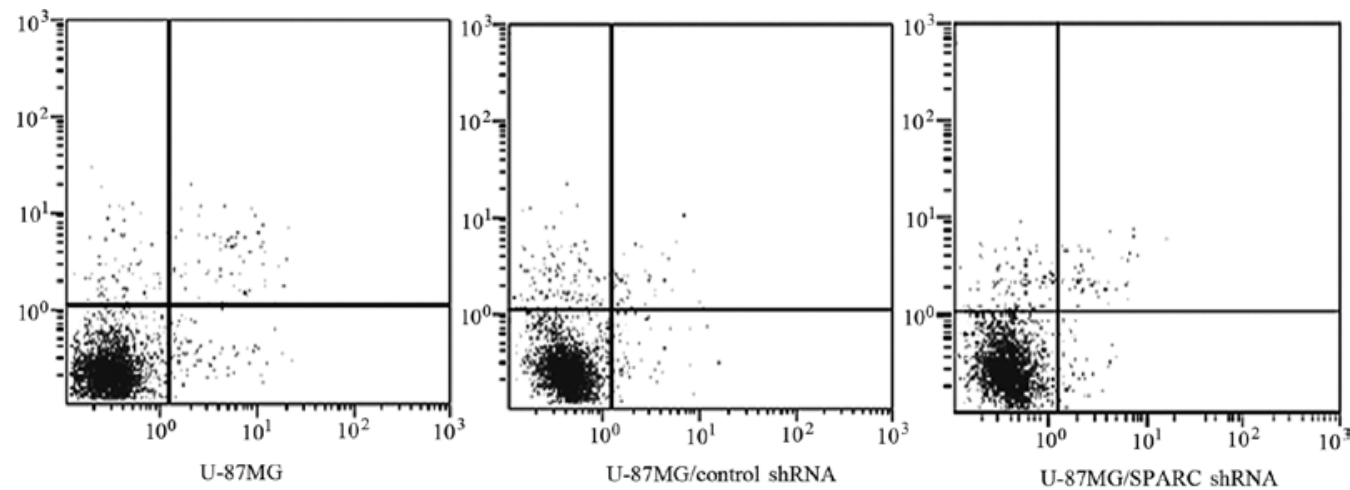

B

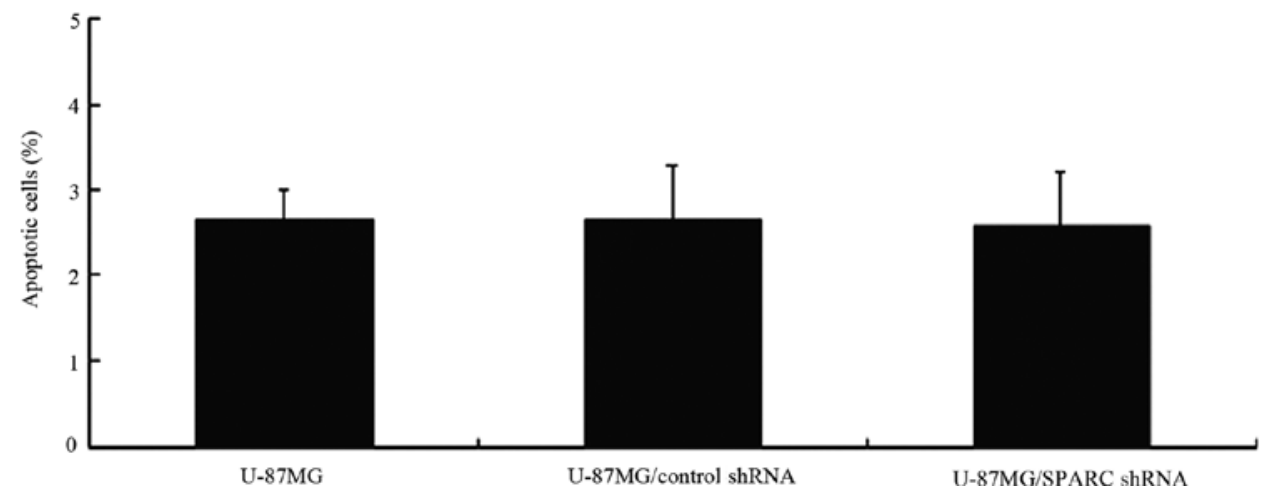

Figure 5. Effect of decreased SPARC expression on cell apoptosis. (A) Representative plots; (B) histograms displayed the average percentages of apoptotic cells and standard deviation, $\mathrm{n}=3$. ${ }^{*}$ Statistical significance, $\mathrm{p}<0.05$.

protein expression of U-87MG cells. As assessed by growth curves, we found that the down-regulation of SPARC expression promoted cell growth during the log phase. Moreover, the number of cells transfected with SPARC shRNA in the plateau phase was larger than that of the control cells. Investigators have demonstrated that increased SPARC expression in glioma 

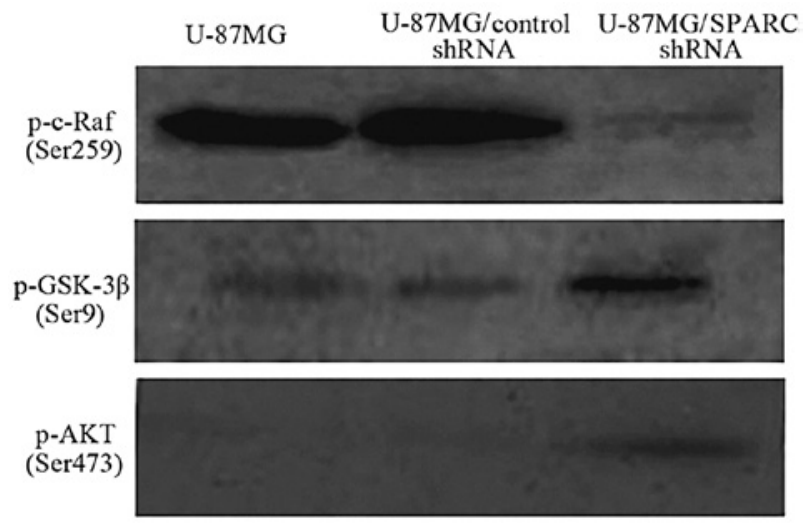

$\mathrm{AKT}$

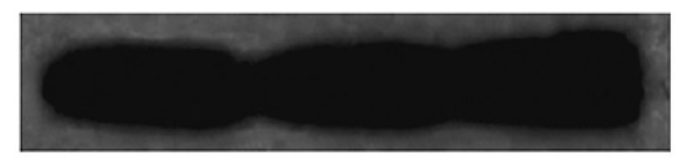

$\beta$-actin

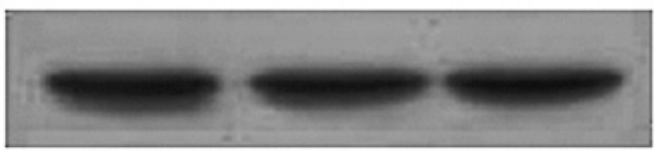

Figure 6. Knockdown of SPARC expression led to the inhibition of p-c-Raf (Ser259) and accumulation of p-GSK-3 $\beta$ (Ser9) and p-AKT (Ser473). Cells were harvested and lysed. Equal amounts of proteins were resolved by SDS-PAGE, transferred to PVDF membranes, immunoblotted with the indicated antibodies and detected using ECL reagent.

cells may delay cell growth (17), which was consistent with our results to some extent. In addition to growth curves, the colony forming efficiency was increased by SPARC shRNA. Thus, whether or not was upregulated or downregulated SPARC affected cell growth. The present study also analyzed whether the effect of SPARC on cell growth was associated with the changes of cell cycle distribution and cell apoptosis. Downregulation of SPARC expression promoted the cell cycle progression from $\mathrm{G} 1$ to $\mathrm{S}$ phase, which induced more cells actively synthesized DNA in the S phase and accelerated cell cycle progression, whereas control cells were blocked in the G1 phase. This process may contribute to the mechanism of growth promotion by SPARC shRNA. However, cell apoptosis was not affected by SPARC shRNA.

Furthermore, a molecular analysis of different signal mediators showed that the level of phosphor-c-Raf (Ser259) was decreased by SPARC shRNA, whereas p-GSK-3 $\beta$ (Ser9) and p-AKT (Ser473) were increased. As a key downstream effector of RAS signaling pathway, the kinase activity of Raf is regulated by phosphorylation of a highly conserved serine residue (Ser259) in the amino-terminal regulatory domain (18). Phosphorylation of Ser259 resulted in Raf inactivation (19). Thus, the decrease of phosphor-c-Raf (Ser259) induced by SPARC shRNA means the activation of c-Raf relatively, which may be one of the mechanisms responsible for growth promotion since c-Raf stimulates cell growth, proliferation and survival through activation of downstream effectors including MEK and ERK (20-22). Antisense oligonucleotides targeted against c-raf kinase resulted in potent anti-proliferative and antitumor effects (23). GSK-3 $\beta$ is a ubiquitously expressed protein serine/threonine kinase. As a core component of certain pathways involved in a number of cancers, such as the Wnt and Hedgehog pathways, GSK-3 $\beta$ plays a role in multiple cell processes including cell growth, differentiation, cell survival, and proliferation (24-26). Decreased GSK-3 $\beta$ expression may promote mammary tumorigenesis and increase the number of cells in the $S$ phase $(27,28)$. Our results showed that the increased phosphorylation of GSK-3 $\beta$ at Ser9 in U-87MG/ SPARC shRNA, which in turn inactivates GSK-3 $\beta$ enzymatic activity (29), may be another signal molecule associated with growth promotion. Akt, a downstream effector of PI-3K, is a serine/threonine kinase that belongs to the AGC family of kinases (30). PI3-K/AKT is a survival pathway. The role of AKT in tumor cell proliferation was shown by its signaling to cyclin D-dependent kinases, which are the central regulators of cell proliferation (31). Therefore, we speculated that the changes of cell growth and cycle distribution mentioned above were partially ascribed to the increased phosphorylation of AKT in U-87MG/ SPARC shRNA.

In conclusion, knockdown of SPARC in U-87MG promoted cell growth, which may be associated with promoting the cell cycle progression from the G1 to S phase. Multiple molecular mechanisms may be responsible for this promotion effect on cell growth and cycle progression, involving the inhibition of p-c-Raf (Ser259) and accumulation of p-GSK-3 $\beta$ (Ser9) and p-AKT (Ser473) in U-87MG. Although the precise signaling pathways leading to growth promotion should be further investigated, our present study may provide help in understanding the role of SPARC in glioma.

\section{Acknowledgements}

This study was supported by grants from the National Natural Science Foundation of China (no. 30870585), Graduate Education Innovation Project of Jiangsu Province (no. CX10B-0442), Graduate Innovation Foundation of Medical College of Soochow University and Natural Science Foundation of Jiangsu Province, China (no. 2D200818). The authors thank Bingyan Li and Jianmei Wan (Jiangsu Provincial Key Laboratory of Radiation Medicine and Protection in Soochow University) for technical support.

\section{References}

1. Furnari FB, Fenton T, Bachoo RM, et al: Malignant astrocytic glioma: genetics, biology, and paths to treatment. Genes Dev 21: 2683-2710, 2007.

2. Bornstein P and Sage EH: Matricellular proteins: extracellular modulators of cell function. Curr Opin Cell Biol 14: 608-616, 2002.

3. Brekken RA and Sage EH: SPARC, a matricellular protein: at the crossroads of cell-matrix communication. Matrix Biol 19: 816-827, 2001

4. Ledda F, Bravo AI, Adris S, Bover L, Mordoh J and Podhajcer OL: The expression on the secreted protein acidic and rich in cysteine (SPARC) is associated with the neoplastic progression of human melanoma. J Invest Dermatol 108: 210-214, 1997.

5. Rumpler G, Becker B, Hafner C, et al: Identification of differentially expressed genes in models of melanoma progression by cDNA array analysis: SPARC, MIF and a novel cathepsin protease characterize aggressive phenotypes. Exp Dermatol 12: 761-771, 2003.

6. Rempel SA, Golembieski WA, Ge S, Lemke N, Elisevich K, Mikkelsen T and Gutiérrez JA: SPARC: A signal of astrocytic neoplastic transformation and reactive response in human primary and xenograft gliomas. J Neuropathol Exp Neurol 57: 1112-1121, 1998.

7. Golembieski WA, Ge S, Nelson K, Mikkelsen T and Rempel SA: Increased SPARC expression promotes U87 glioblastoma invasion in vitro. Int J Dev Neurosci 17: 463-472, 1999. 
8. Rich JN, Shi Q, Hjelmeland M, et al: Bone-related genes expressed in advanced malignancies induce invasion and metastasis in a genetically defined human cancer model. J Biol Chem 278: 15951-15957, 2003

9. Schultz C, Lemke N, Ge S, Golembieski WA and Rempel SA Secreted protein acidic and rich in cysteine promotes glioma invasion and delays tumor growth in vivo. Cancer Res 62: 6270-6277, 2002.

10. Vajkoczy P, Manger MD, Goldbrunner R, et al: Targeting angiogenesis inhibits tumor infiltration and expression of the pro-invasive protein SPARC. Int J Cancer 87: 261-268, 2000.

11. Menon PM, Gutierrez JA and Rempel SA: A study of SPARC and vitronectin localization and expression in pediatric and adult gliomas: High SPARC secretion correlates with decreased migration on vitronectin. Int J Oncol 17: 683-693, 2000.

12. Rich JN, Hans C, Jones B, et al: Gene expression profiling and genetic markers in glioblastoma survival. Cancer Res 65: 4051-4051, 2005.

13. McClung HM, Thomas SL, Osenkowski P, et al: SPARC upregulates MT1-MMP expression, MMP-2 activation, and the secretion and cleavage of galectin-3 in U87MG glioma cells. Neurosci Lett 419: 172-177, 2007.

14. Golembieski WA, Thomas SL, Schultz CR, et al: HSP27 mediates SPARC-induced changes in glioma morphology, migration and invasion. Glia 56: 1061-1075, 2008.

15. Hannon GJ: RNA interference. Nature 418: 244-246, 2002.

16. Meister $G$ and Tuschl T: Mechanisms of gene silencing by doublestranded RNA. Nature 431: 343-349, 2004.

17. Rempel SA, Golembieski WA, Fisher JL, Maile M and Nakeff A: SPARC modulates cell growth, attachment and migration of U87 Glioma cells on brain extracellular matrix proteins. J Neurooncol 53: 149-160, 2001.

18. Mabuchi S, Ohmichi M, Kimura A, et al: Inhibition of phosphorylation of BAD and Raf-1 by Akt sensitizes human ovarian cancer cells to paclitaxel. J Biol Chem 277: 33490-33500, 2002.

19. Zimmermann S and Moelling K: Phosphorylation and regulation of Raf by Akt (protein kinase B). Science 286: 1741-1744, 1999.

20. Dumaz N, Hayward R, Martin J, et al: In melanoma, RAS mutations are accompanied by switching signaling from BRAF to CRAF and disrupted cyclic AMP signaling. Cancer Res 66: 9483-9491, 2006.
21. Smalley KS, Xiao M, Villanueva J, et al: CRAF inhibition induces apoptosis in melanoma cells with non-V600E BRAF mutations. Oncogene 28: 85-94, 2009.

22. Sathornsumetee S, Hjelmeland AB, Keir ST, et al: AAL881, a novel small molecule inhibitor of RAF and vascular endothelial growth factor receptor activities, blocks the growth of malignant glioma. Cancer Res 66: 8722-8730, 2006.

23. Funato T, Kozawa K, Fujimaki S and Kaku M: Increased sensitivity to cytosine arabinoside in human leukemia by c-raf-1 antisense oligonucleotides. Anticancer Drugs 12: 325-329, 2001.

24. Doble BW and Woodgett JR: GSK-3: tricks of the trade for a multi-tasking kinase. J Cell Sci 116: 1175-1186, 2003.

25. Pap $\mathrm{M}$ and Cooper GM: Role of translation initiation factor $2 \mathrm{~B}$ in control of cell survival by the phosphatidylinositol 3-kinase/ Akt/glycogen synthase kinase $3 \beta$ signaling pathway. Mol Cell Biol 22: 578-586, 2002.

26. Sanchez JF, Sniderhan LF, Williamson AL, Fan S, ChakrabortySett S and Maggirwar SB: Glycogen synthase kinase 3betamediated apoptosis of primary cortical astrocytes involves inhibition of nuclear factor kappaB signaling. Mol Cell Biol 23: 4649-4662, 2003.

27. Farago M, Dominguez I, Landesman-Bollag E, Xu X, Rosner A, Cardiff RD and Seldin DC: Kinase-inactive glycogen synthase kinase 3beta promotes Wnt signaling and mammary tumorigenesis. Cancer Res 65: 5792-5801, 2005.

28. Li J, Xing M, Zhu M, et al: Glycogen synthase kinase 3beta induces apoptosis in cancer cells through increase of survivin nuclear localization. Cancer Lett 272: 91-101, 2008.

29. Kim L, Liu J and Kimmel AR: The novel tyrosine kinase ZAK1 activates GSK3 to direct cell fate specification. Cell 99: 399-408, 1999.

30. Hanks SK and Hunter T: The eukaryotic protein kinase superfamily: kinase (catalytic) domain structure and classification. FASEB J 9: 576-596, 1995.

31. Li Q and Zhu GD: Targeting serine/threonine protein kinase B/ Akt and cell-cycle checkpoint kinases for treating cancer. Curr Top Med Chem 2: 939-971, 2002. 